\title{
A Study on the Physical Assets of the Fish Farmers of Meghalaya
}

\section{Dr Ajijur Rahman}

Assistant Professor of Economics, University of Science and Technology Meghalaya, India.

Type of Work: Peer Reviewed.

DOl: http://dx.doi.org/10.21013/jmss.v15.n4.p1

\section{How to cite this paper:}

Rahman, A. (2019). A Study on the Physical Assets of the Fish Farmers of Meghalaya. IRAInternational Journal of Management \& Social Sciences (ISSN 2455-2267), 15(4), 88-98. doi:http://dx.doi.org/10.21013/jmss.v15.n4.p1

(C) Institute of Research Advances.

\section{(cc) BY-NC}

This work is licensed under a Creative Commons Attribution-Non Commercial 4.0 International License subject to a proper citation to the publication source of the work.

Disclaimer: The scholarly papers as reviewed and published by the Institute of Research Advances (IRA) are the views and opinions of their respective authors and are not the views or opinions of the IRA. The IRA disclaims of any harm or loss caused due to the published content to any party.

Institute of Research Advances is an institutional publisher member of Publishers International Linking Association Inc. (PILA-CrossRef), USA. The institute is an institutional signatory to the Budapest Open Access Initiative. Hungary advocating the open-access of scientific and scholarly knowledge. The Institute is a registered content provider under Open Access Initiative Protocol for Metadata Harvesting (OAI-PMH).

The journal is indexed \& included in WorldCat Discovery Service (USA), CrossRef Metadata Search (USA), WorldCat (USA), OCLC (USA), Open J-Gate (India), EZB (Germany) Scilit (Switzerland), Airiti (China), Bielefeld Academic Search Engine (BASE) of Bielefeld University, Germany, PKP Index of Simon Fraser University, Canada. 


\begin{abstract}
The present study was conducted to highlight the Fishery as a source of livelihood among the people of North Garo Hills of Meghalaya. About 30 respondents of different villages of North Garo Hills Meghalaya have consulted together with the information of their practicing Fishery as a source of livelihood. Fish culture is a simple farming system where a farmer can earn more profit than any other agriculture crops and economically it helps the farmer in a short period. By adopting this system of culture, the farmer can easily earn money to depend on their livelihood. The practice of Fish culture provides additional sources of income as well as employment to the native people, while Fish provides lots of nutritive palatable food to each consumer.
\end{abstract}

Keywords: Livelihood, Fisheries, Meghalaya, Income

\title{
Statement of Problem
}

The reservoirs play an important role in the developmental process of a nation and also have an integral role in fisheries and livelihood security of the local community.

With the increase in the population growth reservoirs are becoming an important provider of an animal protein and for the generation of employment in particular to the proper sector of the people. Aquaculture is the farming of aquatic animals and plants globally the aquaculture sector witnessed growth over $8 \%$ per annum in the past two decades and fish production reached about 53 million tons in 2008 . There is about 10 million fish farmer around the world most of them living in developing countries and suing low-intensity production methods.

India is now the second-largest producer of freshwater fish in the world. Fisheries sector occupies an important place in the socio-economic development of the country. It is also a source of livelihood for 14.99 million people in the country. It is a powerful income and employment generator as it stimulates the growth of a number of subsidiaries in industries and is a cheap and nutritious food besides being a foreign exchange earner. The contribution of fisheries to the agriculture GDP has been showing a rising trend.

Aquaculture development is an ongoing part of the extension services of the Meghalaya state Department of Fisheries with responsibilities under the District Fisheries. Offices and superintendents of Fisheries till 1972, the activities for the promotion of fisheries in Meghalaya were part of the development of agriculture.

Meghalaya with its vast inland fisheries resources in the forms of rivers, reservoirs, lakes and ponds and an average rainfall of $1200 \mathrm{~mm}$ offers tremendous scope for developing the fisheries sector but lags behind the harnessing the potential of these natural resources. The available land in most parts of Meghalaya is uneven in terrain that makes it somewhat difficult to develop fisheries on commercial lines.

However, rainwater can be impounded in small ponds for production of fish and inland fisheries and therefore does offer the potential that can be successfully exploited by the people of the state. The state produces about 4,500 tons of fish that is insufficient for a population of 29,66,889 (2001 census) leaving an estimated gap of 14,500 tons annually. As a consequence, most of the fish consumed in the state is imported from another state like Andhra Pradesh.

Fish Production in Meghalaya:

The state has great potential for the development of fisheries. The NRSA data reveal that a large extent of the area is available for fish production. But there are no firm estimates of the production of fish in the state. There are several water bodies in the state, but in the absence of a census, it is difficult to estimate fish production.

\section{Objectives}

Main objectives of the present study are

(a) To study than the socio-economic condition of the fish farmers of the study area.

(b) To explore the physical Assets possess by the fish farmers of the study area.

(c) To study the Government initiative in this regard

\section{A Profile of Meghalaya}

Meghalaya, a narrow strip of land with an area of 22,49 sq. $\mathrm{Km}$ is strategically located in the north-eastern region of the country. One of the smallest states in India, it is bounded by Assam in the North and East and has the international boundary with the neighbouring country of Bangladesh in the South and West. The Profile of 
Meghalaya is also contained to identify the protective cottage and small scale industries by analyzing available human and materials resources, infrastructure facilities like transport and communication, power, water, industrial sheds, industrial area and growth centres, finance and the existing level of development in the industrial front, etc. An attempt has also been made in the profile to highlight the problems confirmed by the small scale sector in the state and analyze them in the light of the information collected to guide the entrepreneurs in overcoming the obstacles. An attempt has also been made to throw light in the lines of new investment opportunities based on the analysis of assures, infrastructure facilities, demand pattern and ancillary requirement of the state.

\section{Methodology}

The study is based on both primary and secondary data

a) Secondary Data: - Secondary data has been collected from Dissertations, Government report books, new paper, articles, published and unpublished journals, etc.

b) Primary Data: - Primary data has been collected through direct personal investigation questionnaire and interview schedule from the fish Farmers. Data collected has been done in the month of April 2018.

Communication was done with fish farmers in their own language.

Sampling Method: - Random sampling method used while collecting data from different villages.

Sample Size: - The study was conducted in ten villages of North Garo Hills District of Meghalaya. These are Mendipathar, Khaldang, Manignaj, Horinkata, Babupra, Gangdubi, Resubelpara, Nolbari, Miapara and Dilma. The researcher has selected 3 fisherman beneficiaries in each village; hence the sample size is 30 .

\section{Review of Related Literature}

CMFRI(1977)' points out that fisherman of our country has districts traditional of their own. They belong to all the major religion namely Hinduism, Christianity, Islam, and several communities which differ from state to state. In society, the fishing community occupied a low status. Majority of the fisherman belong to economically weaker section and follow traditional methods of fishing employing indigenous crafts and gears. The average size of the fisherman family varies between 4-7 and 8.6 in different states. By and large, they are perennially in deleted to the middleman who advances financial help to them in times of need in return for their entire catch assessed at a low price. Several factors such as low social status, poor economic conditions, illiteracy, heavy enter service of middleman, traditional fishing equipment and method of fishing, low production rate and income influence the socio-economic condition of fisherman. Right from the beginning of the first five-year plan, this sector has been receiving considerable attention from the Government.

Various schemes for providing housing facilities, dispensaries, and community amenities, approach road, etc. are given priority. Organization attempts are made to promote fishery Co-operative in our country.

Panikkar et al., (1981) studied the impact of the introduction of mechanist boats on the socio-economic conditions of a traditional fisherman when they are supplied with mechanized boats. To study this impact, Calicut region was selected where Agriculture Reference Development Corporation (ARDC) has supplied 50 mechanized boats of size 36 inches so that each boat was allotted to seven fisherman families; thus involving 350 fisherman families in this venture. The study indicates importance in the economic condition of the fisherman families of pathiangadi (near Calicut) which receive credit facilities from ARDC. The introduction of mechanization induce many fishermen to shift from traditional to mechanized fishing which resulted in increased lending and created more employment opportunities in the net making, ice-plant and workshop operation, sorting, auctioning, transporting and fish trading. The absence of such economic activities in the neighbouring El athur village in a pointer to the significance of availabilities of credit facilities to invest in improved fishing techniques.

Kalawar(1981) examined the living conditions of a fisherman in Maharashtra. According to him, the living condition of the whole is deplorable. Owing to lack of economic been a result the females have to bear most of the burden of economic activity. In debtless in the fisherman community is widespread. Necessary infrastructure 
by way of communication and transport facilities, water supply and power should have to be provided on a priority basis. This creates scope for setting up agro-based and fisheries based industries.

Libroro (1985), investigated the economics of small scale fisheries particular, total catch, costs and returns, employment, and income for the different types of craft and gear in the Philippine Municipal fishing.

Chidambaram et al.,(1997) have studied marine fish supplies in Tiruchender area. They have described fishing operations, financial requirements, and profitability in fishing and production problems encountered by the fisherman They have also given policy suggestions for the development of the fisherman.

Ganesh Kumar et al., this study was conducted in all the major coastal states and some selected inland states to understand the domestic marketing of fish in India. Fisherman cooperative society has been found to be ' 0.98 , ' 8.89, ' 6.61, ' 4.50, ' 6.00 and ' 3.51 , respectively. The marketing efficiencies for Indian major carps (IMC), Sardine and seer fish have been found to vary from $34 \%$ to $74 \%$ depending on the length of the market channel. The study has highlighted the need for formulating a uniform market policy for fishes for easy operation and regulation, so that the country's fish production is efficiently managed and delivered the consuming population, ensuring at the same time remunerative prices to the fishers.

\section{Socio-Economic Profile of the Fish Farmers in North Garo Hills}

In this section, an attempt has been made to analyze the Socio-Economic Profile of the Fish farmers such as Gender Distribution, Age, Distribution, Educational Qualification, Family Size, Income, etc. These factors are intimately related to their socio-economic conditions.

Table 1: Gender Distribution.

\begin{tabular}{|c|c|c|}
\hline Gender & No. of Respondents & Percentage (\%) \\
\hline Male & 25 & $75 \%$ \\
\hline Female & 5 & $25 \%$ \\
\hline Total & $\mathbf{3 0}$ & $\mathbf{1 0 0} \%$ \\
\hline
\end{tabular}

Source: field survey

Figure-1: Gender Distribution

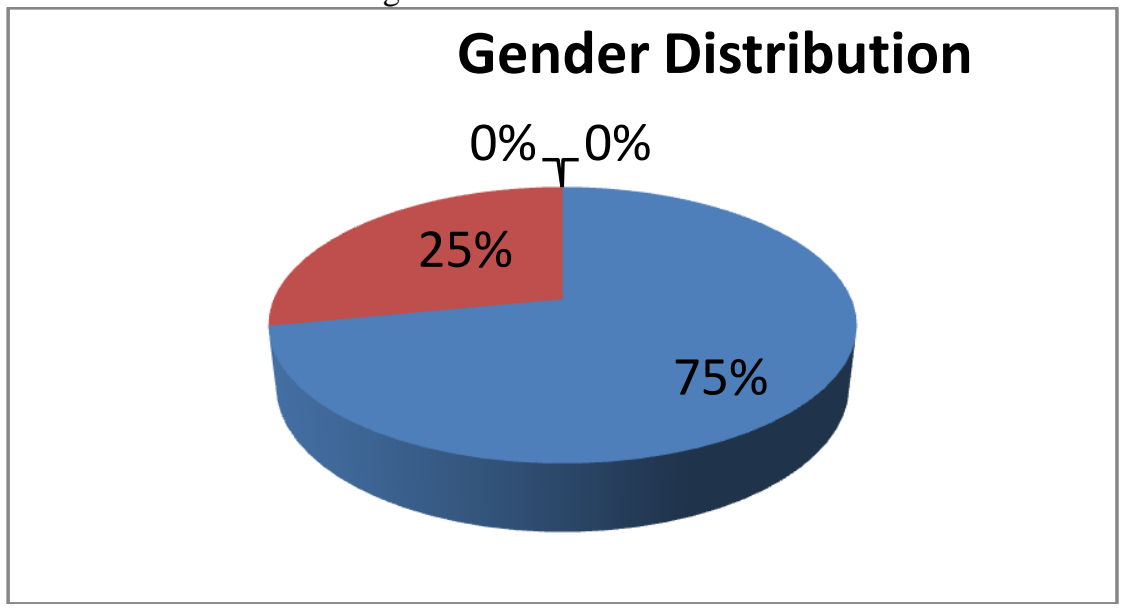

It can be seen from table- 1 that Out of 30 respondents, $75 \%$ are and $25 \%$ are female. It is clear that the majority of the Fish farmer was Male in the study are. Females are also participating in fish farming in the study area.

Table No. 2: Age Group of the Respondents

\begin{tabular}{|c|c|c|}
\hline Age Group of the Respondents & No. of Person & Percentage (\%) \\
\hline $21-30$ & 3 & $15 \%$ \\
\hline $31-40$ & 8 & $25 \%$ \\
\hline $41-50$ & 8 & $25 \%$ \\
\hline $50>$ & 11 & $35 \%$ \\
\hline Total & $\mathbf{3 0}$ & $\mathbf{1 0 0} \%$ \\
\hline
\end{tabular}

Source: Field survey 
Figure No. 2: Age Group of the Respondents

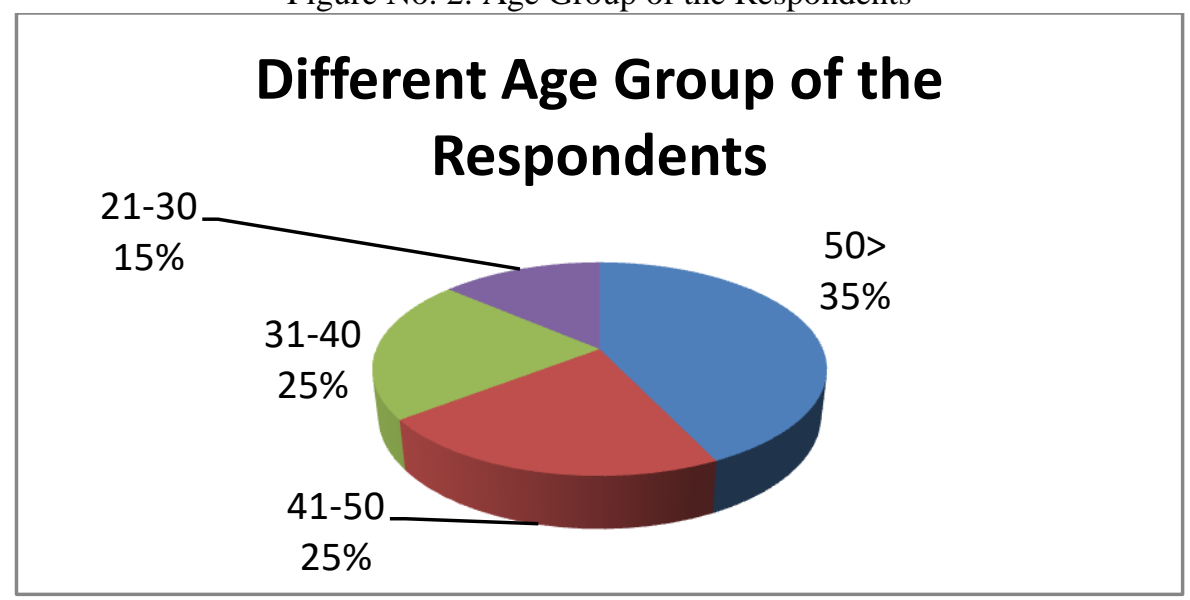

It can be seen from Table- 2 that 11 respondents belong to the 50 and above age group, 8 respondents belong to 41-50 age group, 8 respondents belong to 31-40 age group and 3 respondents belong to 21-30 age group. This implies that majority of the respondent were 50 and above age group in the study area.

Table-3: Educational Qualification

\begin{tabular}{|c|c|c|}
\hline Educational Qualification & No. of Person & Percentage \\
\hline Illiterate & 15 & $55 \%$ \\
\hline School Level & 13 & $35 \%$ \\
\hline Graduate & 2 & $10 \%$ \\
\hline Post Graduate & 0 & $0 \%$ \\
\hline Total & $\mathbf{3 0}$ & $\mathbf{1 0 0} \%$ \\
\hline
\end{tabular}

Source: Field survey

Figure-3: Educational Qualification

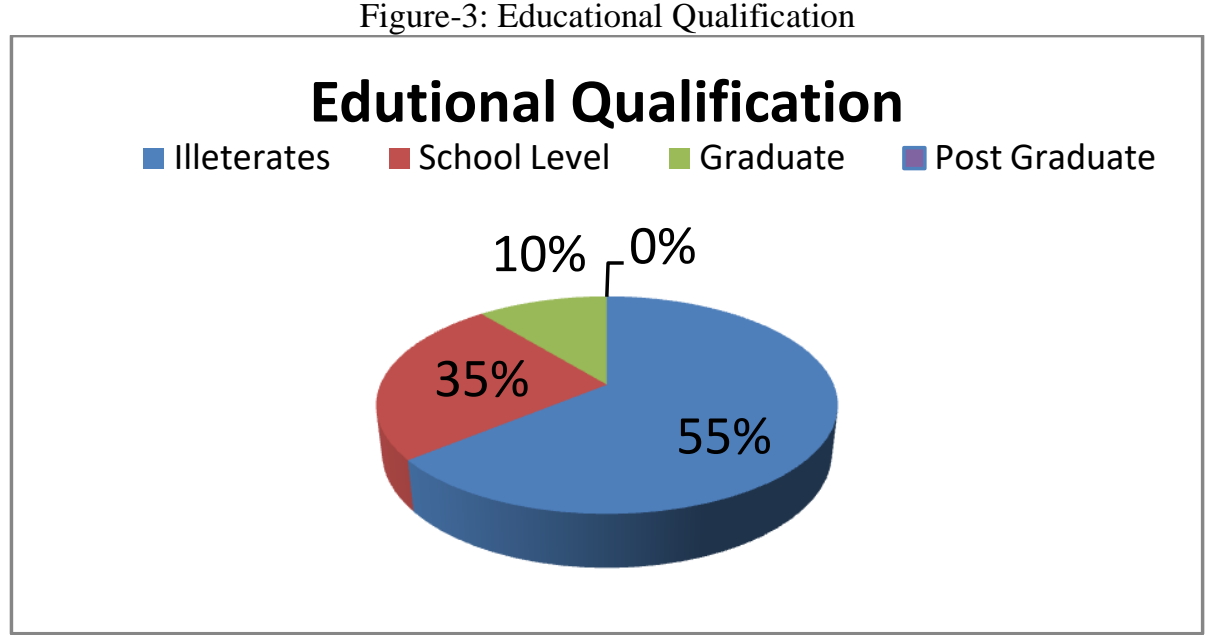

Table- 3 shows that out of 30 respondents, $55 \%$ were Illiterate, $35 \%$ were educated up to school level, $10 \%$ have educated up to Degree level and none of them has reached up to Post Graduation Level. The results show that majority of the respondents were at Illiterate and were school level as well. None of the Post Graduate respondents was found during the survey.

Table No.4: Occupational Pattern of the Respondents

\begin{tabular}{|c|c|c|}
\hline Occupation & No. of Respondents & Percentage (\%) \\
\hline Service & 3 & $11.5 \%$ \\
\hline Business & 7 & $19.5 \%$ \\
\hline Wage Earner & 7 & $19.5 \%$ \\
\hline
\end{tabular}




\begin{tabular}{|c|c|c|}
\hline Agriculture & 10 & $38 \%$ \\
\hline None & 3 & $11.5 \%$ \\
\hline Total & $\mathbf{3 0}$ & $\mathbf{1 0 0} \%$ \\
\hline
\end{tabular}

Source: Field Survey

Figure-No.4: Pie chart representation of the occupation pattern of the Respondents.

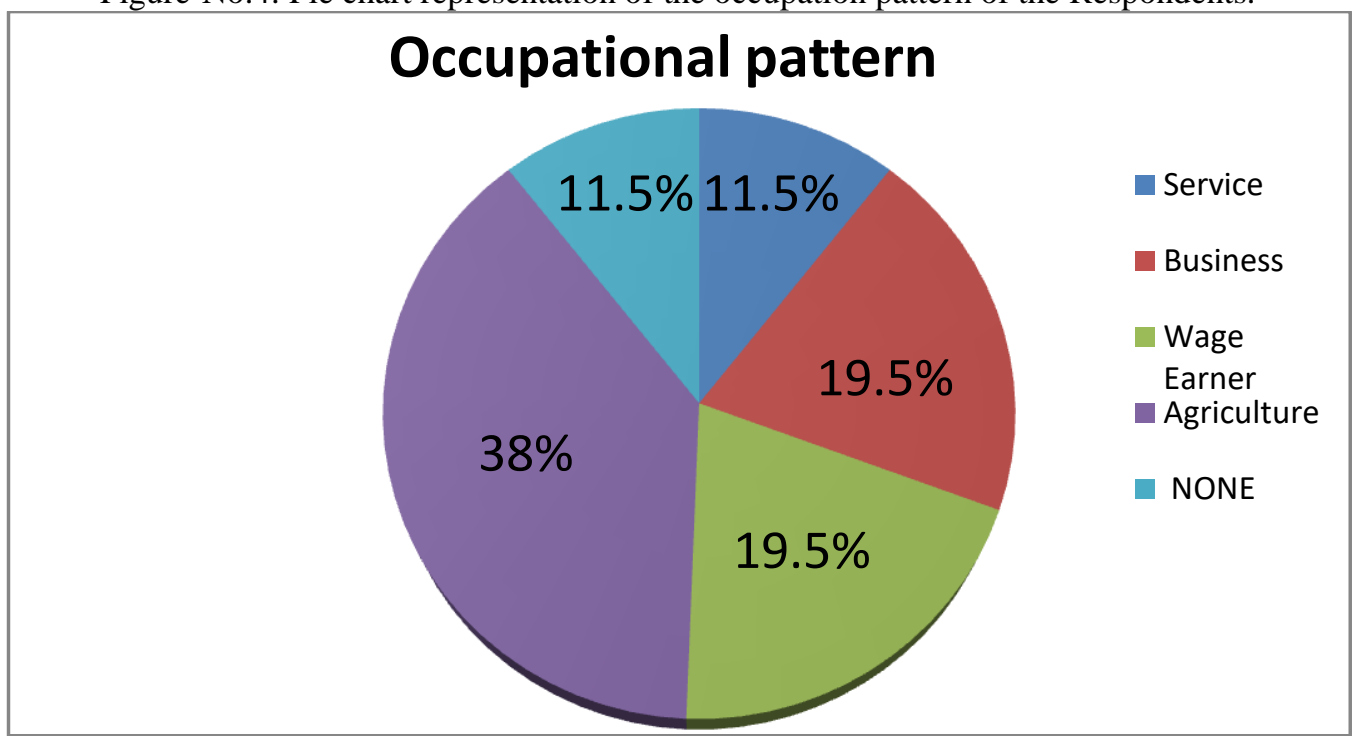

Table-4 indicates that Agriculture is the main occupation of the North Garo Hills with $38 \%$ engaged in it. 11.5 $\%$ of the respondents have service i.e., Govt. Service while $19.5 \%$ are engaged in Business and $19.5 \%$ of the respondents are Wage Earner and the other $11.5 \%$ do not have any other occupation.

Table-5: Distribution of Respondents to their Household Assets

\begin{tabular}{|c|c|c|}
\hline Household Assets & No.of Respondents & Percentage (\%) \\
\hline Movable Assets & 5 & $12.5 \%$ \\
\hline Immovable Assets & 25 & $87.5 \%$ \\
\hline Total & $\mathbf{3 0}$ & $\mathbf{1 0 0 \%}$ \\
\hline
\end{tabular}

Source: Field Survey

Table-5 shows that out of 30 respondent 5 have movable assets such as Cars and Bikes. And 25 of the respondents have immovable assets such as Land, House, etc. It implies that some of the respondents are landless farmers.

Figure-5: Column representation of the House assets of the Respondents

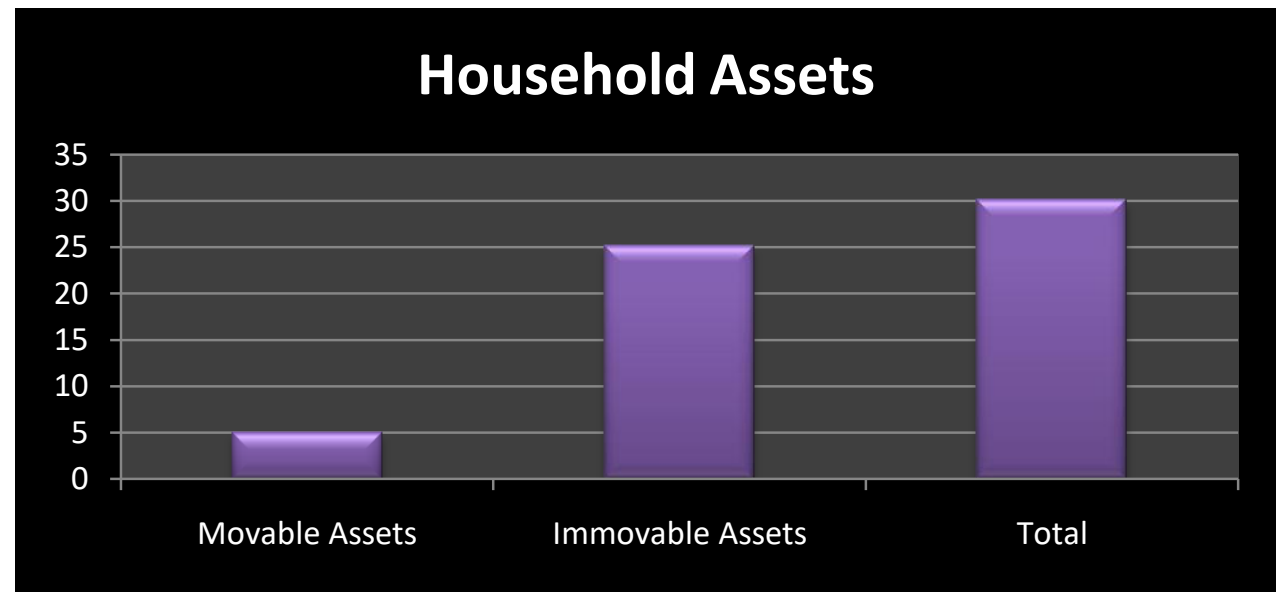


Table-6: Distribution of the main income source of the Respondents.

\begin{tabular}{|c|c|c|}
\hline Income Source & No. of Respondents & Percentage (\%) \\
\hline Monthly Salary & 5 & $15 \%$ \\
\hline Wage & 2 & $5 \%$ \\
\hline Husbandry & 0 & $0 \%$ \\
\hline Agriculture & 20 & $70 \%$ \\
\hline Business & 3 & $10 \%$ \\
\hline Treading & 0 & $0 \%$ \\
\hline Pension & 0 & $0 \%$ \\
\hline Rental Income & 0 & $0 \%$ \\
\hline Total & $\mathbf{3 0}$ & $\mathbf{1 0 0} \%$ \\
\hline
\end{tabular}

Source: Field Survey

Table- 6 reveals the main income source of the respondents. It has been observed that $70 \%$ of the respondents reported that Agriculture is the main income source of their family. $15 \%$ of respondents are govt. service holder and $5 \%$ of them reported daily wage earner and $10 \%$ have reported business.

Figure-6: Bar representation of the Income source of the Respondents

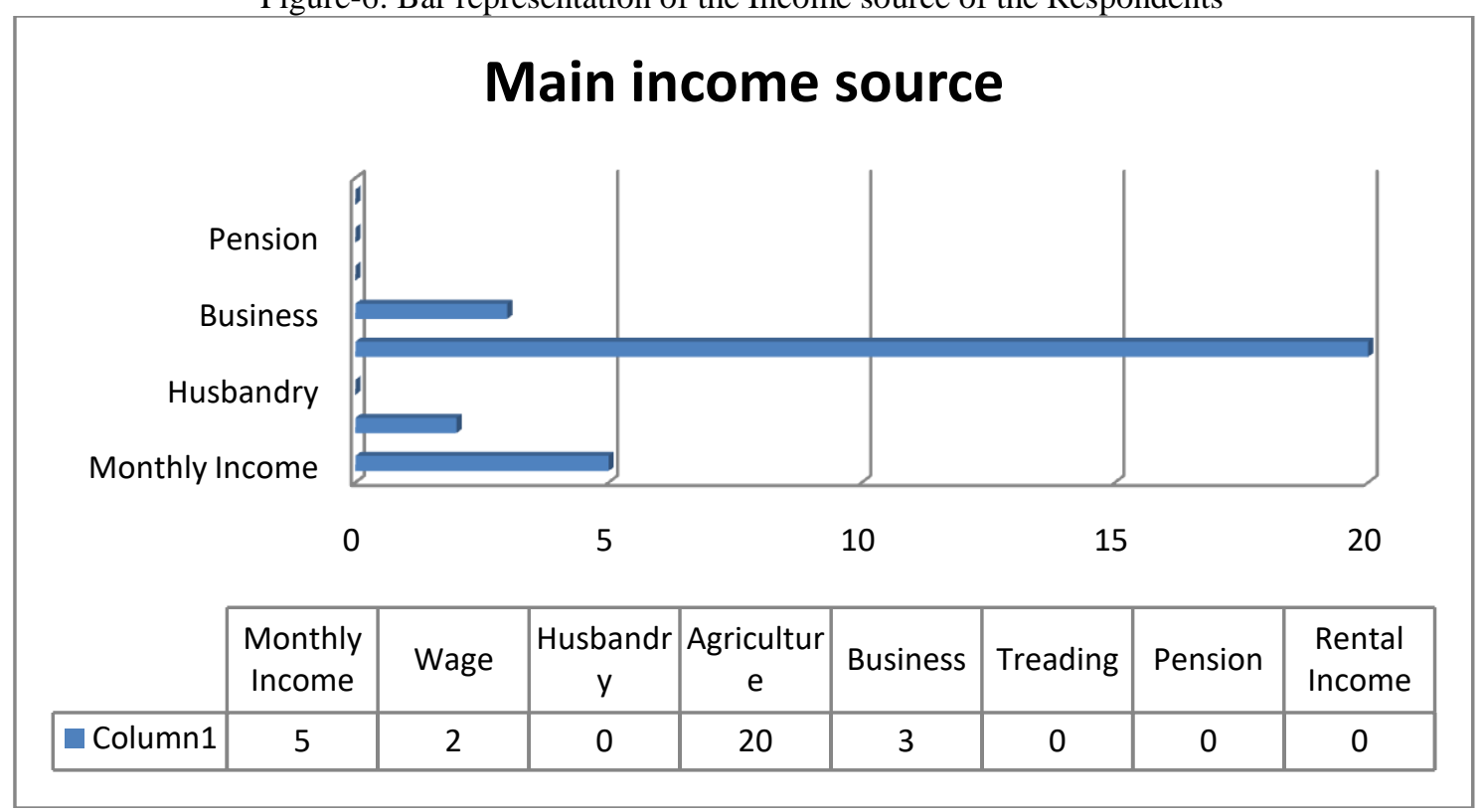

Table-7: Distribution of Household expenditure of the Respondents

\begin{tabular}{|c|c|c|c|c|c|c|c|}
\hline \multirow{2}{*}{ Serial No. } & \multirow{2}{*}{ Expenditure on } & \multicolumn{5}{|c|}{ Amount spend per month(in Rs) } & \multirow{2}{*}{ Total } \\
\cline { 3 - 7 } & & $\begin{array}{c}\text { Below } \\
\mathbf{1 0 0 0}\end{array}$ & $\begin{array}{c}\mathbf{1 0 0 0}- \\
\mathbf{2 0 0 0}\end{array}$ & $\begin{array}{c}\mathbf{2 0 0 0}- \\
\mathbf{5 0 0 0}\end{array}$ & $\begin{array}{c}\text { Above } \\
\mathbf{5 0 0 0}\end{array}$ & \multirow{2}{*}{ Nil } & \\
\hline 1 & Food & 5 & 5 & 15 & 5 & & 30 \\
\hline 2 & Electricity & 30 & & & & & 30 \\
\hline 3 & Health & 25 & & & & 3 & 30 \\
\hline 4 & Water & & & & & & 30 \\
\hline 5 & $\begin{array}{c}\text { Education for } \\
\text { Children }\end{array}$ & 10 & 5 & 7.5 & 7.5 & & 30 \\
\hline 6 & Miscellaneous & 30 & & & & & 30 \\
\hline
\end{tabular}

Source: Field Survey

Table-7 indicates that 5 respondents spend below Rs. 1000 on Food and 5 respondents fall in the category of Rs. 1000-2000 and other 15 respondents spend 2000-5000 and other 5 respondents spend above 5000 on their Food. 30 respondents have reported that total expenditure on Electricity is below Rs. 1000. Similarly, 25 respondents reported that their expenditure on health is below 1000 and the other 5 respondent's expenditure was less than 
Rs. 500. However, their expenditure on Water was Nil. It means that they have their own water source. 10 respondents reported that their expenditure for Education of their Children is below Rs.1000, 5 respondents belong to the range of Rs.1000-2000 and other 7.5 respondent's expenditure was Rs.2000-5000 and the other 7.5 respondent's expenditure was above 5000. Likewise, the expenditure of Electricity is below 1000, so also, their miscellaneous expenditure is also below Rs. 1000.

\section{FISHERY AND SOCIO-ECONOMIC STATUS:}

The billfishes, swordfish tunas, along with dolphin- fish, Wahoo and other pelagic species, support valuable recreational and commercial fisheries in many coastal regions. But studies suggest that population of big ocean fish, including bluefin and bigeye tuna, swordfish, the marlins, and many oceanic sharks, may have declined as much as 90 per cent over the last 50 years. Efforts to restore them have been hindered in large part due to the non-selective nature of the fishing gears and methods used to target these fish commercially, most notably pelagic long lines, also commonly known as surface or drift long lines.

Some would contend that it is how many fish you catch, not how you catch them, that are important to sustaining fish populations. But this misconception ignores a half-century of evidence to the contrary. Our collective experience with non-selective fishing gears is this;

Excessive bycatch and waste, resulting in one-quarter of the global catch being discarded as unwanted, prohibited or protected species, an inability to effectively control fishing mortality for any single species in a fishery that opportunistically targets and catches multiple species, destructive impacts on marine life and the ability of fishermen coastal fishing communities to survive, much less thrive , and disproportionate management and regulatory costs imposed on taxpayers and regional economies .

Best fishing practices for conserving and managing big ocean fish require transitioning fisheries away from the large-scale use of indiscriminate, ecologically-harmful fishing gears to more selective, sustainable fishing methods that provide an economically feasible, low-by catch alternative. Fortunately, those alternative methods exist.

Rivers, streams, manmade small /big reservoirs, bigger Beels, and lakes can be classified under capture fisheries when the human invention is required for capturing fishes from those water bodies with the help of various fish capture devices like Rods and Line, traps and gears are Gill Nets, Drag Nets, Bag Nets, etc.

Manmade ponds and tanks, as well as barrages small Lakes and Beels which are not flood affected, can be brought under fish culture by implementing scientific fish seed rising fish farming technologist to enhance the production of fish seed and then rising it to adult fish. Practicing of fish culture provides additional sources of income as well as employment to the native people, while fish provide lots of nutritive and palatable food to its consumers.

Before taking fish culture/pond, it is important to know the basic requirement of fish. If the requirement is fulfilled, fish will certainly grow faster and thereby the farmer will get more profit.

- The water body in the form of pond/tank or barrage/lakes may be considered as the house of fish.

- It may be of any shape and size.

- For effective manage, the pond should be rectangular in shape and water area growing out pond may between 0.2 ha to 2 ha.

- Water may be available for a maximum period of 6-12 months.

- Minimum 1-1.2 M and maximum 1.5-2 M water depth.

- Supplementary feed in the form of Rice Polish Mustard Oil calin 1:1ratio mixed with required quantity of fish meal, minerals, and vitamins, etc. for better growth of cultivable fish in the culture system.

\section{PROBLEM OF FISHERY}

Even though the Northeast has vast potential for augmenting its fish production, a large number of constraints hindering fisheries development are yet to be tackled. Some of these are briefly discussed. Non-availability of quality fish seed inadequate number has always been a constraint in the region. Unspecified but considerable quantities of fish seed are brought into the region from West Bengal by road and through three fish seeds market setup in Borpeta Road, Rangiya and Dhekiajuli in Assam. The problem is further confounded by the low- 
temperature regime of high attitudes, where breeding and rearing is difficult. Even in Assam and Tripura were a large number of carp hatcheries have been operating, considerable regional variations in seed availability occurs. Adequate facilities are not available for growing fish spawn into fingerlings stage to stock the beels and reservoirs.

The Northeastern region receives very high rainfall during the Southwest monsoon season (June-September), which coupled with its unique undulating topography and situation of most of its rivers and associated wetlands, wrecks havocs on the floodplain areas every year. Floods are one of the major constrains to aquaculture development of a commercial scale in the region especially in Assam and Tripura (which are more prone to floods) because it submerges the aquaculture ponds and pens constructed in marginal areas of beels and reservoirs. This results in loss of stocked fishes as well as damage to pond dykes and pens structures. Also, water current associated with floods can carry the entered cage aquaculture structure installed inbeel/reservoirs. As aquaculture and fisheries enhancements have progressed in the region, a fish disease in aquaculture system has emerged as a notable problem. Fortunately, the problem does not vary acute except for the occasional outbreak of the epizootic Ulcerative syndrome.

In many fisheries, current roles and regulations are not strong enough to limit fishing capacity to a sustainable level. This particular case for the high seas, where there are few international fishing regulations. Even when fisheries regulations exist, they are not always implemented or enforced. For example, many countries have still not ratified, implemented, or enforced, international regulations such as the UN Convention on the Law of the Sea and the UN fish stocks agreement. Lack of political will is also responsible for failures to adopt by catch reduction devices, for example, customs agencies and also retailer is not always ensuring that the fish entailing their country and shops is caught legally and in a sustainable way. As a result, the consumer is unwittingly supporting poor management by purchasing fish from unsustainable fisheries. Only when our seafood is traceable can markets and legal system be effective and reward sustainable practices, whilst dater the irresponsible. Many fisheries management bodies do not heed scientific advice on fish quotas and set catch limits above the recommended maximum amount.

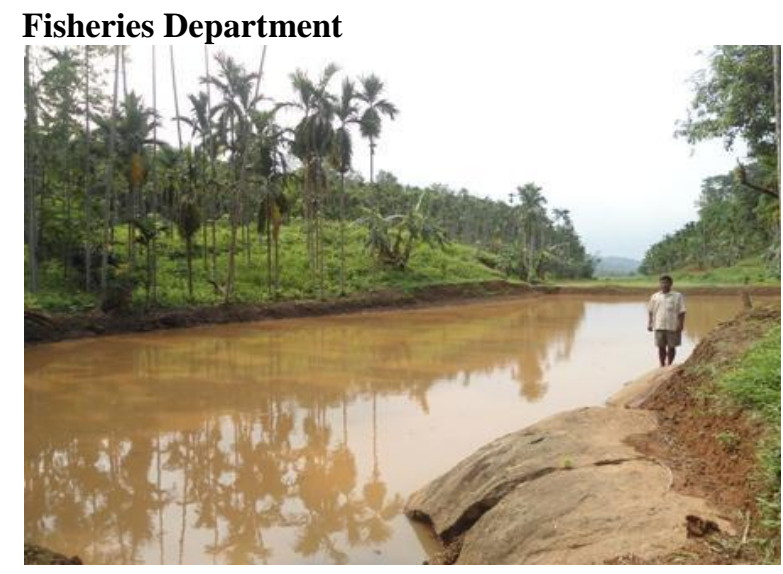

The Department of the fisheries was created by the Govt. of Meghalaya with the sole intention of addressing all issues relating to Fishery matters in the state especially with regard to further enhance developmental activities with special emphasis to fish farming and fish production. Its main agenda to create and enhance the skill and knowledge of fish farming by giving financial assistance in kind or in cash, providing training and exposure visit workshop and orientation programmers on the latest technology adopted by progressive fish farmers/entrepreneurs etc. The Department is also giving awareness and promoting for creation of fish sanctuaries to protect and conserve the indigenous and endemic fish species. In order to increase fish production and to minimize the supply of fish seeds from outside the state, the department is also creating Eco-hatcheries/FRP hatcheries. The department is mainly focusing on the constitution of individual fisher pond as well as community pond to enhance the fish production as well as creating more water bodies thereby reducing the import of fishier from other states which will benefit the farmers to earn their income and improve their livelihood. In order to promote fish culture/aquaculture in the state the Govt. of Meghalaya launched "Meghalaya State Aquaculture Mission" with a powerful slogan "Dependence to self -sufficiency" under which six(6) Mini Missions are there and can be seen /downloaded from MSAM Website while implementing this ambitious programmed of the Govt. The department is under tremendous pressure due to the lake of manpower and with present law and order scenario, especially in Garo Hills regions. The fishery farm at Gangdubi was constructed during the erstwhile undivided Assam and later handed over to the fishery department when Meghalaya got statehood with the creation ofResubelpara sub-division, the office of the fishery officer was also set up at Gangdubi fish farm and now recently been upgraded to a District Office headed by the Superintendent of Fisheries. 


\section{FINDINGS, RECOMMENDATIONS AND CONCLUSION}

Major Findings: The major findings of the study are given below:

- The present study tries to examine fishery as a source of livelihood among the tribal's of North Garo Hills, Meghalaya. The survey was undertaken with a view to understanding various factors such as the income of the respondents, methods of cultivation, generating employment, etc. It was found that people of North Garo Hills are benefited cultivation by practicing fishery as their sources of livelihood. While comparing the villages which were found in the survey, we founded the practice and yield by the people of Gangdubi village seemed to be high then another village.

- It is evident from the study that most of the respondent is male among the total respondent only $25 \%$ were female and $75 \%$ were male.

- Most of the ponds were created in the Farmers owned land.

- All the respondents were belonged to schedule tribe category (ST).

- Most of the respondents are illiterate.

- Out of 30 respondent s 5 have movable assets such as cars and bikes. And 25 of the respondents have immovable assets such as land, house, etc.

- Fish farming such as activity opened up opportunities for people to get employment.

- High travelling cost and excessive documentation were some of the problems faced by the respondents.

- Other than fisheries like Rice cultivation, Poultry, Pig farming, Cattle farming, Vegetable plantation, Fruit plantation, Tea plantation, Ginger plantation, Battle nut plantation, Turmeric plantation, etc. are doing by the farmers which have become as a means of livelihood for the fish farmers.

- The researcher had found that all of the fish farmer family does not have to pay their water bills.

- Most of the fish farmer family have used ring well for their drinking purpose.

- The respondent's family used sanitation for their daily life.

- The maximum number of the fish farmer family did not get any facilities or any help from the Govt.

- Most of the fish farmer family does not use gas for their cooking. They use chulha for their cooking. (Chulha is the traditional Indian cooking stove used for indoor cooking.)

- All the farmers sell their produce by themselves through the local market.

\section{RECOMMENDATIONS}

In light of the findings of the study, observations made during the period of the survey and discussions made with fish farmers in the field of study, the following recommendations have been put forward:

- Before taking fish culture in a tank/pond, it is important to know the basic requirement of fish. If requirements are fulfilled, fish will certainly grow faster and their by farmers will get more profit.

- Due to destroyed or damaged by natural climates like a flood, soil erosion, collapse, or crack of the pond, fish farmers face a serious problem in reconstructing the pond. The Govt. should re-inspect the site from time to time and refinance for the renovation of the pond.

- Fish farmers face a lot of trouble and problem because of the thief, most of the fish farmer did not get any benefit because of the thief. So, if the Govt. can help the fish farmers with barbed wire fencing or another fencing to overcome this problem.

- In order to uplift the living condition of the fishing population, more infrastructural facilities should be furnished, which will, in turn, reduce their strains and stress for their better living in the villages.

- The farmer needs proper training.

- Need to improve the socio-economic status.

\section{Conclusion}

The comparative study was undertaken between the 10 villages of North Garo Hills within the duration of one month. The findings of the research show that all the respondents involved in Fishery are economically sound. It is a source of income in many peoples of North Garo Hills District of Meghalaya. Fisheries in Meghalaya has great potential, especially with the rearing of species varieties like Grass carp, Common carp, Silver carp, Mrigal, Rohu, Catla, Gonius, etc. The Govt. of Meghalaya has identified fisheries as a key sector and decided to assist the people to develop fish pond has help the people of Meghalaya to generate employment and to improve their income and standard of living.

Technology research and development would also help in promoting the fisheries sector in the state. The study showed that the physical Assets of the Fish Farmers of Meghalaya are quite good. 


\section{References}

[1]. CMFRI, Kochi (1977) CMFRI Annual Report 1977. Technical Report, CMFRI, Kochi.

[2]. Indian Journal of Fisheries 57(4):81-84 Jan2010

[3]. International Journal of Humanities \& Social Science Studies (IJHSSS) 2(5): 283-290 May 2016

[4]. Ahmad J, Ahmed A-F, Natarajan R, Saif A-Y (2008) Assessment of groundwater vulnerability in the coastal region of Oman using DRASTIC index method in GIS environment. Environ Monit Assess 147:125-138

[5]. Balasubramaniam, S., Mohan, B., Kandoran, M.K. and Nair, A.K.K.,(1991) Paper presented at the National workshop on Low Energy Fishing, Society of Fisheries Technologists (India), Cochin 2.

[6]. Balasubramanian, S., (2001) Socio-Economic Status of Marine Fishermen in Two Fishing Villages of Orissa, Fishing Technology, 38(1): pp.51-55

[7]. Boyce, J. K.1994. "Inequality as a cause of environmental degradation” Ecological Economics, 11: 169-178. 